\title{
Disseminated herpes simplex virus infection with hepatitis in an adult renal transplant recipient
}

\author{
DP WALKER, M LONGSON, W LAWLER, $\uparrow$ NP MALLICK, ${ }^{*}$ JS DAVIES, $\dagger$ \\ RWG JOHNSON
}

From the North Manchester Regional Virus Laboratory, the *Department of Renal Medicine and the University of Manchester $\dagger$ Departments of Pathology and $\ddagger$ Surgery, Manchester Royal Infirmary, Oxford Road, Manchester

SUMMARY A rare occurrence of disseminated herpes simplex virus infection with hepatitis in an adult renal transplant recipient is described.

Disseminated herpes simplex virus (HSV) infection is well recognised in neonates and produces a high mortality. ${ }^{12}$ In contrast it is very rare in adults; less than a score of cases have been documented, and only nine cases appear to have been recorded in the United Kingdom in the last 32 years. ${ }^{3-7}$ This report describes disseminated HSV infection with hepatitis in a 39-year-old female renal transplant recipient.

\section{Case report}

JP, aged 39, developed nephrotic syndrome in 1962 and went on to regular home dialysis in 1968. In 1975 thyrotoxicosis was diagnosed and treated medically. In 1978 she developed severe dyspnoea on exertion and mixed aortic valve disease was found. Ventricular extra-systoles were noted and atrial fibrillation occurred intermittently during dialysis. Cadaver renal transplantation was carried out on 2 February 1980. Dialysis was required in the initial posttransplant period but the graft then functioned well. On the fourth day after transplantation, she developed ventricular fibrillation and required resuscitation and cardioversion. Her further course was complicated by persisting multifocal ventricular ectopic beats resistant to drug treatment and congestive heart failure supervened.

From the 6th day, liver enzyme activities were raised. Alanine-aminotransferase activity was initially $113 \mathrm{IU} / 1$ but over $1000 \mathrm{IU} / 1$ by the 23 rd day. The serum bilirubin remained normal throughout. There was no clinical suggestion of liver failure. She collapsed suddenly on the 23 rd day and could not be resuscitated.

Accepted for publication 11 March 1981

\section{CLINICAL VIROLOGY FINDINGS}

Before laboratory isolation of HSV, there had been no clinical reason to suspect herpetic disease. The first indication was the isolation of the virus on the 13th day from urine collected three days earlier. This isolation was considered most unusual and the patient was carefully reviewed for a possible source Particular attention was paid to the external geni talia, but no lesions were seen. The uterine cervis was not examined. There were no oral or skin vesicles and the patient was afebrile.

Three days later, saliva collected on the same day as the urine yielded HSV, but again no source of virus was detected clinically. On the 20th day urine passed five days earlier also yielded HSV, but by then, three typical herpetic lesions were noted on the labia. The patient appeared reasonably well, and the urinary virus was ascribed to contamination from the herpes genitalis. However, 24 hours later, there was marked deterioration in the patient's condition, with florid herpetic stomatitis, scattered vesicles on fingers, hands, arms and trunk (about 20 lesions in all) and the genital sores had extended to involve the whole vulva.

NECROPSY AND HISTOLOGICAL FINDINGS

At necropsy, numerous vesicular lesions were present in and around the mouth, around most finger nails, and on the external genitalia. There was no significant oedema or superficial lymphadenopathy.

The heart (440 g) was enlarged by moderate left and mild right ventricular hypertrophy. There was extensive old and very recent, predominantly subendocardial, anterolateral myocardial infarction due to severe coronary artery atherosclerosis. The aortic outflow tract was narrowed by atheroma of the 1044 
proximal ascending aorta and mild calcific aortic stenosis.

The liver (2010 g) had a very mottled cut surface with multiple irregular, rather ill-defined yellowish areas $1-4 \mathrm{~mm}$ in maximum diameter; histologically, these were foci of necrosis distributed randomly throughout the lobules, and there was only a mild associated infiltrate by polymorphs, lymphocytes and macrophages. Many hepatocytes at the periphery of the necrotic areas contained eosinophilic intranuclear inclusions (Cowdry Type A).

The spleen was enlarged (460 g) and unduly soft on section. Histologically very occasional small foci of necrosis were present, and a few cells in those areas contained intranuclear inclusions.

The adrenals appeared normal microscopically, but multiple small foci of necrosis with very little associated inflammatory cell infiltration and intranuclear inclusions were seen microscopically.

The patient's kidneys showed "end-stage" renal disease. Other organs including brain, pituitary, thyroid, salivary glands, gastrointestinal tract, internal genitalia and the transplanted kidney, were normal.

\section{VIROLOGICAL LABORATORY FINDINGS}

The patient was reviewed weekly for evidence of virus infection following transplantation. Blood, saliva, throat swabs, and urine were collected and liver was obtained at necropsy. Specimens for isolation were inoculated into monkey kidney, HEp-2 and human embryo fibroblast cell cultures. Specimens taken two days after transplantation did not yield virus, but urine and saliva taken at 10, 15, and 18 days yielded HSV. Virus isolated from liver was identified as HSV type 1 using methods described by Pauls and Dowdle. ${ }^{8}$

To demonstrate HSV antigen in all organs examined histologically, two techniques were used. One involved an indirect immunofluorescence method, after digestion of the tissues with trypsin, ${ }^{9}$ using rabbit antiserum to HSV type 1 and fluoresceinconjugated sheep anti-rabbit antibody (Wellcome Laboratories); the other was an immunoperoxidase method using antisera to HSV type 1 and 2 (Dakoimmunoglobulins, supplied by Mercia Brocades Ltd, Surrey). With both techniques, viral antigens were demonstrated in liver and adrenal; these were maximal around the periphery of necrotic areas (Figure). The pattern of immunoperoxidase staining was similar with antisera to both HSV types 1 and 2 , illustrating the considerable antigenic relation between the two strains.

To confirm the histological and immunofluorescence results, small pieces of formalin-fixed liver tissue were processed for electron microscopy and

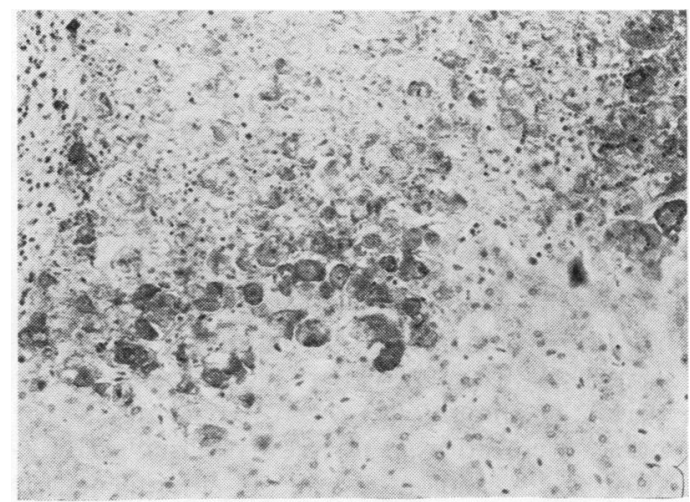

a

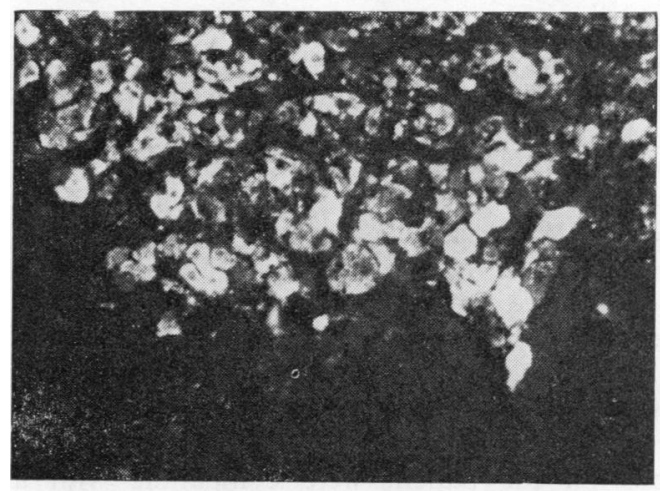

b

Appearance of herpes simplex virus (HSV) antigen in liver as shown by (a) immunoperoxidase staining using antiserum to $H S V$ type $1 \times 250(b)$ indirect immunofluorescence using antiserum to HSV type $1 \times 300$.

embedded in Spurr resin. ${ }^{10}$ Thin sections of this material were viewed in the electron microscope, and although tissue preservation was poor, numerous herpes virus-like particles could be recognised in the cytoplasm and nuclei of many hepatocytes.

The diagnosis of HSV infection was supported by serological studies. During the year preceding transplantation, persistently low concentrations of complement-fixing (CF) antibody to HSV (CF titre $1 / 10$ ) had been found. HSV CF antibody titres remained at $1 / 10$ on the 5 th and 10th days after transplantation but had risen to $1 / 160$ on the 18 th and 22nd days. IgM antibodies to HSV were detected in the last two sera but not in serum taken 26 days before transplantation. Low unchanging concentrations of CF antibody to cytomegalovirus (titre $1 / 10$ ) were present in all sera examined both before and after transplantation. 


\section{Discussion}

Disseminated HSV infection in adults is usually accompanied by stomatitis ${ }^{411}$ and as in infants, the outcome is usually, but not invariably, fatal. One of the few patients to survive was a 24-year-old pregnant woman who recovered from severe illness but delivered a macerated fetus. ${ }^{4}$ Disseminated HSV infection in both children and adults may be caused by HSV type 1 or type $2.1^{13}$ In adults, it is often associated with pre-existing clinical conditions where cellular immunity has been compromised-for example, severe burns, ${ }^{14}$ thymic dysplasia, ${ }^{13}$ Hodgkin's disease ${ }^{15}$ and after steroid treatment for asthma ${ }^{16}$ and renal transplantation. ${ }^{11}$ The observation of HSV-specific IgM complement-fixing antibodies in the patients (heat-treated) sera may have been spurious, resulting from the banding of heatinduced aggregates of HSV-specific IgG antibody with the IgM immunoglobulin fraction in the sucrose density gradients. Rheumatoid factor was not detected in any of the sera. Patients with recurrent HSV disease have been found to have titres of HSV-specific IgM antibodies which remained constant before and after a recurrence. ${ }^{17}$ In the case described here quantitative data on HSV-specific IgM antibody concentrations were not available for comparison.

The clinical, histological and virological investigations on the patient were compatible with a diagnosis of disseminated HSV infection although the cause of death was myocardial infarction. Serological evidence indicated a recrudescence of latent $\mathrm{HSV}$ type 1. Previous observations in cases of HSV hepatitis in adults were confirmed and in addition, immunofluorescence and immunoperoxidase labelling techniques demonstrated HSV antigen within areas of necrosis. In retrospect, it is clear that insufficient attention was paid to the original HSV isolate obtained from urine. Although it was appreciated that the isolation of HSV from urine was most unusual and the possibility of a viraemia was considered, the full significance of the finding was not grasped. Indeed, a week later the patient developed clinical herpes genitalis, and this merely strengthened an erroneous belief in specimen contamination. It is now clear that the original isolate was a finding of utmost importance, and had the patient been treated at this stage-that is, 14 days after transplant, with vidarabine or acyclovir ${ }^{18}$ she night have been spared cataclysmic dissemination of HSV.

This case further demonstrates the association between immunosuppression and disseminated HSV with hepatitis in adults. It is probable that steroid treatment is instrumental in exacerbating the in fection in renal transplant recipients.

\section{References}

1 MacCallum FO. Generalised herpes simplex in the neonatal period. Acta Virol $1959 ; 3$, suppl:17-21.

${ }^{2}$ Becker WB, Kipps A, McKenzie D. Disseminated herpes simplex virus infection. Its pathogenesis based on virological and pathological studies in 33 cases. Am J Dis Child 1968;115:1-8.

${ }^{3}$ Kipping RH, Downie AW. Generalised infection with the virus of herpes simplex. $\mathrm{Br}$ Med J 1948;i :247-9.

${ }^{4}$ Flewett TH, Parker RGF, Philip WM. Acute hepatitis due to herpes simplex virus in an adult. J Clin Pathol $1969 ; 22: 60-6$

5 Juel-Jensen BE. Severe generalised primary herpes treated with cytarabine. Br Med J 1970;ii:154-5.

- Juel-Jensen BE, MacCallum FO. Herpes simplex, varicella and zoster. London: Heinemann, 1972:50-2.

${ }^{7}$ Dowling RH, Henry K. Clinicopathological conference: non-responsive coeliac disease. Br Med J 1972 ;iii:624-31.

${ }^{8}$ Pauls FP, Dowdle WR. A serologic study of herpesvirus $\mathbb{D}$ hominis strains by microneutralisation tests. J Immunol 1967;98:941-7.

๑ Swoveland PT, Johnson KP. Enhancement of fluorescent $\bar{\partial}$ antibody staining of viral antigens in formalin-fixed $\stackrel{\mathbb{D}}{-}$ tissues by trypsin digestion. J Infect Dis 1979;140:758-64 $\vec{\ominus}$

${ }^{10}$ Spurr AR. A low-viscosity epoxy resin embedding mediua $\infty$ for electron microscopy. J Ultrastruct Res 1969;2, 31-43.

11 Anuras S, Summers R. Fulminant herpes simplex hepa titis in an adult: Report of a case in a renal transplant recipient. Gastroenterology 1976;70:425-8.

12 Goyette RE, Donowho EM, Hieger D, et al. Fulminant herpesvirus hominis hepatitis during pregnancy. Obstet $\mathbb{D}$ Gynecol 1974;43:191-5.

${ }^{13}$ Sutton AL, Smithwick EN, Seligman SJ, Kim DS. Fatal $\overline{\bar{\sigma}}$ disseminated herpes hominis type 2 infection in an adult 3 with associated thymic dysplasia. Am J Med 1974;56: 545-53.

14 Foley FD, Greenwald KA, Nash G, Pruitt BA. Herpes infection in burned patients. $N$ Engl J Med 1970;282:응 652-6.

${ }^{15}$ Lee JC, Fortuny IE. Adult herpes simplex hepatitis. Hum Pathol 1972;3:277-81.

16 Diderholm H, Stenram U, Tegner KB, Willen R. Herpes $\delta$ simplex hepatitis in an adult. Acta Med Scand 1969;186: 151-5.

${ }^{17}$ Kurtz JB. Specific IgG and IgM antibody responses in herpes simplex virus infections. J Med Microbiol 7:33341.

18 Oxford JS. Inhibition of herpes virus by a new compound -acyclic guanosine. J Antimicrob Chemother 1979;5: 333-4.

Requests for reprints to: Dr DP Walker, North Manchester Regional Virus Laboratory, Clinical Laboratories, Manchester Royal Irifirmary, Manchester M13 9WL, England. 